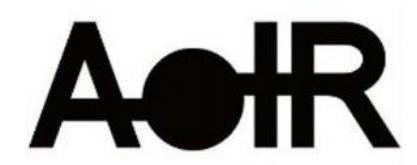

Selected Papers of \#AoIR2021:

The 22nd Annual Conference of the

Association of Internet Researchers

Virtual Event / 13-16 Oct 2021

\title{
FROM WATCHED AT WORK TO WATCHED AT HOME: WORKPLACE SURVEILLANCE DURING A PANDEMIC
}

\author{
Jessica Vitak \\ University of Maryland, College Park \\ Michael Zimmer \\ Marquette University
}

\section{Background}

The future of work is increasingly intertwined with the widespread collection of employee data for workplace monitoring, safety and efficiency tracking, predictive analytics, and performance evaluations (Mateescu \& Nguyen, 2019). While surveilling employees has existed as long as there has been employment, there is newfound interest in the use of digital monitoring tools: a 2019 study of 239 large corporations found that $50 \%$ were using "nontraditional" surveillance methods, including logging and analyzing phone calls, scrutinizing emails and social media posts, and tracking who attends meetings, an increase from 30\% four year earlier (Wartzman, 2020).

Recent advances in pervasive monitoring and data collection in the workplace include the use of prediction and flagging tools, biometrics data collection through sensors and microchips, remote monitoring and GPS tracking, and algorithmic management. Increasingly, these data are used to make meaningful decisions about employeesincluding whether they should be hired, promoted, or fired—based on faceless algorithmic processes (Köchling \& Wehner, 2020). Most concerning is that such surveillance practices and impacts are not evenly distributed across workers (Levy, 2016; Rosenblat \& Stark, 2016).

The COVID-19 lockdowns caused significant shifts in work practices-and in workplace monitoring. While unemployment soared in some sectors, many office workers began working from home. Early evaluations suggest this shift has not reduced the amount of work-related surveillance. Rather, it has spawned renewed interest in monitoring those working-from-home with increasingly invasive tools, including monitoring software to record employees' web browsing and active work hours, monitoring attentiveness in videoconferences, and mandating always-on webcam rules (Harwell, 2020). Even when

Suggested Citation (APA): Vitak, J., \& Zimmer, M. (2021, October). From watched at work to watched at home: Workplace surveillance during a pandemic. Paper presented at AoIR 2021: The 22nd Annual Conference of the Association of Internet Researchers. Virtual Event: AolR. Retrieved from http://spir.aoir.org. 
employees return to the office, additional measures will likely be taken to track everything from location to body temperature to coworker proximity (Hepler, 2020).

This study begins unpacking the sociotechnical implications of shifting work surveillance practices due to COVID-19, focusing on how evolving and emergent workplace surveillance practices may impact workers. We are motivated by the concern that as pandemic restrictions ease, employers may continue to extend at-home surveillance practices while also instituting new monitoring in the workplace. This "function creep" (Ball, 2010) raises concerns that increased digital surveillance will lead to reduced agency, control, and independence at work (Ganster \& Fusilier, 1989), no matter where those activities are taking place.

\section{Study Overview}

This study was motivated by two research questions:

RQ1: What concerns do American office workers have about workplace surveillance practices while working from home?

RQ2: What concerns do American office workers have about workplace surveillance practices when they return to the office?

Our survey instrument was designed for workers who had been affected by pandemic restrictions. The survey included demographic and background questions, and asked questions about respondents' work environment before and during the pandemic, including their perceived job security, satisfaction, stress, and control, as well as the monitoring practices used by their employer.

The survey also included factorial vignettes (Wallander, 2009) to address our RQs and unpack how multiple factors affect workers' attitudes toward workplace monitoring. Respondents viewed 35 scenarios; each scenario had the same format, with four factors that randomly changed in each scenario. These factors were derived from Nissenbaum's (2010) work on privacy as contextual integrity: data attributes, the purpose for data collection, the actors who would see data collected, and the transmission principle associated with data collection. By using contextual integrity as a guiding framework, we can identify workers' "pain points" regarding information flows in the workplace. See Figure 1 for an example vignette from the study.

Data was collected in November 2020 via Qualtrics, which was contracted to recruit American adults who had been employed by the same company since at least the beginning of 2020 and who worked at home for at least part of the pandemic. After data cleaning, the final dataset included 645 respondents (53\% male, $84 \%$ White, average age $=44)$. Most respondents $(77 \%)$ had at least a bachelor's degree, and the most common jobs were in Information Technology (23\%), Business/Finance (15\%), and Education (14\%). 
Your company will begin collecting and monitoring employee data through new company software. Your body temperature and other health measures may be collected to maximize work efficiency. This data will be made available to your direct supervisor. This data collection will only occur while you are logged in to work applications from home.

\begin{tabular}{lccccccc}
\hline & $\begin{array}{c}\text { Strongly } \\
\text { Disagree }\end{array}$ & Disagree & $\begin{array}{c}\text { Somewhat } \\
\text { disagree }\end{array}$ & Neutral & $\begin{array}{c}\text { Somewhat } \\
\text { agree }\end{array}$ & Agree & $\begin{array}{c}\text { Strongly } \\
\text { agree }\end{array}$ \\
$\begin{array}{l}\text { This form of } \\
\text { monitoring is } \\
\text { appropriate. }\end{array}$ & $\bigcirc$ & $\bigcirc$ & $\bigcirc$ & $\bigcirc$ & $\bigcirc$ & $\bigcirc$ & $\bigcirc$ \\
$\begin{array}{l}\text { This form of } \\
\text { monitoring would } \\
\text { concern me. }\end{array}$ & $\bigcirc$ & $\bigcirc$ & $\bigcirc$ & $\bigcirc$ & $\bigcirc$ & $\bigcirc$ & $\bigcirc$
\end{tabular}

Figure 1. Sample vignette from the survey.

\section{Overview of Results}

We first conducted a series of paired t-tests to compare respondents' attitudes toward their work environment before the pandemic with their attitudes in November. Over the course of the pandemic, workers reported a significant increase in their job stress and decreases in their job satisfaction, security, and knowledge of how their employer monitored them.

When asked about the types of monitoring their employer conducted at the start of $2020,78 \%$ selected at least one from a list of options; $12.9 \%$ said their employer did not monitor them, while $9 \%$ were unsure. Monitoring time and attendance $(61.4 \%)$, work email (40.5\%), physical location (32.9\%), and network access $(28.9 \%)$ were most common. However, when asked whether their employer had begun using new technologies or changed workplace monitoring policies, $23 \%$ were unsure, suggesting confusion about what policies may have changed due to the pandemic.

Because each respondent read 35 vignettes, our dataset includes more than 22,000 evaluations of how appropriate and concerning a scenario was perceived. We used linear mixed models to identify differences in factors while controlling for repeated responses from each respondent. Through this approach, we were able to identify specific data attributes, purposes, actors, and transmission principles that are most likely to be viewed as problematic forms of workplace monitoring. Full results will be shared in the conference presentation.

\section{Discussion and Implications}

COVID-19 upended work in many ways and forced companies and employees to reconsider best practices for getting work done-both in the traditional workplace as well as at home. This blurring of public and private boundaries now under surveillance is concerning, as is the potential for such surveillance practices to continue after the pandemic. This study provides insights into workers' perceptions of current workplace 
monitoring practices and, more importantly, their concerns regarding potential future uses of workplace monitoring. It also raises questions about how such reductions in privacy and independence at work may have negative outcomes on worker productivity, satisfaction, and well-being.

\section{References}

Ball, K. (2010). Workplace surveillance: An overview. Labor History, 51, 87-106.

Ganster, D. C., \& Fusilier, M. R. (1989). Control in the workplace. International Review of Industrial and Organizational Psychology, 4, 235-280.

Harwell, D. (2020, April 30). Managers turn to surveillance software, always-on webcams to ensure employees are (really) working from home. Washington Post. https://www.washingtonpost.com/technology/2020/04/30/work-from-home-surveillance/

Hepler, L. (2020, April 28). Welcome back to the office. This Ring will track your location and temperature. Protocol. https://www.protocol.com/touchless-doors-biometric-ringsproptech-cornavirus

Köchling, A., \& Wehner, M. C. (2020). Discriminated by an algorithm: A systematic review of discrimination and fairness by algorithmic decision-making in the context of HR recruitment and HR development. Business Research, 13, 795-

848. https://doi.org/10.1007/s40685-020-00134-w

Levy, K. (2016). Digital surveillance in the hypermasculine workplace. Feminist Media Studies, 16, 361-365. https://doi.org/10.1080/14680777.2016.1138607

Mateescu, A., \& Nguyen, A. (2019). Algorithmic management in the workplace. Data \& Society Research Institute. https://datasociety.net/library/explainer-algorithmicmanagement-in-the-workplace/

Nissenbaum, H. (2010). Privacy in context. Stanford University Press.

Rosenblat, A., \& Stark, L. (2016). Algorithmic labor and information asymmetries: A case study of Uber's drivers. International Journal of Communication, 10, 3758-3784.

Wartzman, R. (2019, March 20). Workplace tracking is growing fast. Most workers don't seem very concerned. Fast Company. https://www.fastcompany.com/90318167/workplace-tracking-is-growing-fast-mostworkers-dont-seem-very-concerned 